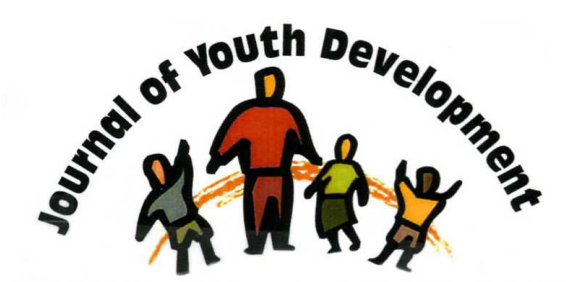

Bridging Research \& Practice

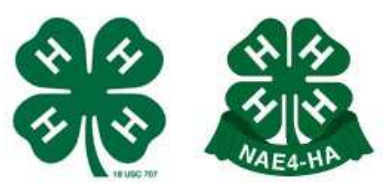

\title{
A Longitudinal Comparison of Parent and Child Influence on Sports Participation
}

\author{
Arena Chang \\ University of California, Irvine \\ Joseph L. Mahoney \\ University of California, Irvine
}




\title{
JOURNAL OF YOUTH DEVELOPMENT \\ bridging research and practice

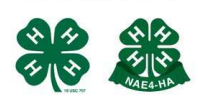

Volume 8, Number 3, Winter 2013

Article 130803FA004

\section{A Longitudinal Comparison of Parent and Child Influence on Sports Participation}

\author{
Arena Chang and Joseph L. Mahoney \\ University of California, Irvine
}

\begin{abstract}
Drawing on expectancy-value theory, this study examines children's motivational attributes and parental influences on how children spend their leisure time in middle childhood and adolescence. Specifically, the study examined if parent encouragement and beliefs (i.e., perceived importance of sports and perceived child ability) and child motivation (expectancy and value for sports) are predictive of sports participation over the course of middle childhood and adolescence. Parent and child reports are compared using data from the Childhood and Beyond (CAB) longitudinal study. Findings reveal that parent beliefs and encouragement and child motivation were positively associated with sports participation in middle childhood. Both parental influences and children's motivation measured in middle childhood were predictive of time spent participating in adolescence. However, only parent influences were predictive of whether the child continued to participate in sports in adolescence.
\end{abstract}

\section{Introduction}

There are many benefits associated with participating in organized youth sports ranging from physical health to psychosocial competence and educational attainment. For example, childhood obesity is a global epidemic that is a concern of parents and policymakers alike. Involvement in organized sports activities can be an effective method to ensure regular physical activity (Mahoney, 2011). In addition to physical health benefits, participation in organized sports activities is associated with increased school attendance, educational expectations, academic achievement, and positive social relationships. Participation is also associated with reduced chances of school dropout and criminal offenses, especially for at-risk youth (Barber, Eccles, \& Stone, 2001; Harrison, \& Narayan, 2003; Mahoney, Larson, Eccles, \& Lord, 2005). Overall, participation in high-quality extracurricular activities, such as sports, is a productive use of youth's leisure time and can provide unique opportunities for development (Larson, 2000). 
However, although many of associated benefits referenced above have been noted for adolescents, as children get older their participation rates in organized sports declines (Mahoney, Vandell, Simpkins, \& Zarrett, 2009; National Household Survey on Drug Abuse, 2002). Considering the benefits, more research is needed to identify and overcome barriers or deterrents to continued sports participation. Therefore, it is important to learn what factors are influential in getting and keeping youth involved from childhood to adolescence. Drawing on expectancy-value theory, this study examines the influences of parents as socializers (parental encouragement and beliefs) and youth motivation (expectancies and values for sports) in relation to organized sports participation. The study examines if parental influence and child motivation during middle childhood are predictive of youth participation and time spent in sport during adolescence.

\section{Expectancy-Value Model for Choices and Behaviors}

Eccles' expectancy-value model (Eccles, 1993; 2007) of motivation is often used to explain individual differences in choice behaviors, engagement, persistence, and achievement. Expectancies are self-predictions of how well one will do on an upcoming task, and values are one's beliefs about the reasons he/she might engage in a task (Wigfield, \& Eccles, 2000). Task value is composed of four components: attainment value (importance of the activity to one's self-identity), intrinsic value (interest and enjoyment one gets from the task), utility value (usefulness of the activity to fulfill short- or long-term goals) and cost (what the child has to give up to do a task). In colloquial terms, one's expectancies answer the question, "Can I do it?" and one's values answer, "Do I want to do it?"

The current expectancy-value model has strong support for achievement-related choices in educational settings (Schunk, Pintrich, \& Meece, 2008) and has been applied to explain choices related to extracurricular activities and occupations (Eccles, 1994; Fredricks, \& Eccles, 2005; 2006; Pugliese, 2011). The expectancy-value framework can explain why one child pursues and persists in sports whereas another child opts out. For example, a child who has high selfperceptions of sports competence (expectancy) and places high importance on sports (value) is more likely to participate in organized sports activities in his/her leisure time than a child with low expectancies and value for sports.

In the early school years, children's sports preferences (i.e., motivation) and the choices and opportunities parents provide for them equally predict the type of sports children choose to play (Jacobs, Vernon, \& Eccles, 2005). However, with development, parent guidance diminishes as the child's autonomy in decision-making increases. Despite the heavy influence parents have in early childhood, some research shows that time spent with parents, emotional closeness, and yielding to parent decision-making all decrease in adolescence (e.g., Paikoff, \& Brooks-Gunn, 1991).

However, motivation research stresses the importance of youth motivation in middle childhood and adolescence - the developmental periods when motivation for school subjects and organized extracurricular activities begins to decline (Eccles, 1993; Jacobs, et al., 2002). Thus, it is unclear how youth motivation predicts sports participation across development, particularly in middle childhood and adolescence, and its relation to parental influences as a predictor of later participation in adolescence. In particular, it is less clear how decreased parental influence and youth's choice behavior in adolescence (Eccles, 1993; Montemayor, \& Hanson, 1985) are associated with whether youth decide to continue sports participation and the depth of their participation in adolescence. To the degree that benefits of youth sport participation depend on 
long-term, stable involvement in athletic activities, understanding the relations between youth choice behavior and parent influence over time remains an important gap in the knowledge base (Bohnert, Fredricks, \& Randall, 2010).

\section{Parent Socializing Processes}

One of the commonly reported reasons for participating in extracurricular organized activities given by adolescents is encouragement and support from friends or parents (Fletcher, Elder, Mekos, 2000; Huebner, \& Manicini, 2003). According to Eccles' expectancy-value framework, parents help to guide their children's engagement and performance on tasks by influencing youth self-perceptions and task values. Specifically, parents engage in socializing behavior and communicate their values to influence their children's behaviors in two ways-directly through encouragement and indirectly through their beliefs regarding the importance of the activity and their perception of their child's ability.

\section{Direct Influence: Parental Encouragement}

One of the commonly reported reasons adolescents participate in extracurricular organized activities is encouragement from parents (Fletcher, et al., 2000; Huebner, \& Manicini, 2003). Encouragement can take the form of verbal support of youth behavior or through the provision of materials and opportunities (e.g., sports equipment or taking them to sporting events or practice), thereby structuring their children's experiences.

Eccles (2007) theorized that parental encouragement influences youth's choice behaviors, such as in extracurricular activities, in three ways.

1) First, parent encouragement may support youth's self-view of ability and value for that particular activity.

2) Second, parental encouragement can be indicative of their personal values for a specific activity, which may motivate students to engage in that activity and internalize the same values as their parents.

3) Third, parental encouragement of the child may produce a positive affective state in children, which can create a positive association for that particular activity.

This study examines the first two pathways-the relation of parent encouragement to youth expectancies and values for sports.

Studies examining parents' role in children's choice of extracurricular activities show that parenting styles and behaviors (such as warmth and clear rules and expectations) are positive indicators of adolescent participation in organized activities (Eccles, 1993; Fletcher, et al., 2000; Fredricks, \& Eccles, 2005; Mahoney, et al., 2009). A meta-analysis (Pugliese, \& Tinsley, 2007) found that common parenting practices used to successfully elicit physical activity in children were encouragement, modeling, and instrumental support. These findings are not surprisingchildren can only learn about what they are exposed to. Thus, parents play a critical role of introducing children to organized activities, providing them with the opportunity to develop the skills and interest needed to pursue those activities independently.

\section{Indirect Influence: Parents Beliefs}

Parents possess many beliefs about their children's abilities, which should affect motivationallylinked outcomes. These beliefs include parents' expectancies and values for an activity. Such beliefs, particularly parents' perceptions of their children's competencies and likely success, predict children's subsequent self and task beliefs (see Eccles, 2007 for review). Studies that 
support this relationship for sports found that parents' perceptions of child ability are related to children's beliefs and sports participation concurrently and over time (Bois, Brustad, Chanal, \& Trouilloud, 2005; Fredricks, \& Eccles, 2002; 2005).

Parents' beliefs about the value of an activity also influence children's beliefs and participation (Jacobs, \& Eccles, 2000). Parents demonstrate their value for an activity through explicit or implicit messages, such as rewarding or encouraging their children, getting involved in the activity with the child, or role modeling by playing a sport. For example, parents' value for sports were linked with elementary children's sports beliefs and participation even when parents' socialization practices were taken into account (Fredricks, \& Eccles, 2005), suggesting that parents convey their values of sports to children in subtle ways.

The majority of studies on parents' beliefs have been based on samples with mothers. Less is known on how fathers contribute to individual differences in children's athletic motivation and behavior from an expectancy-value perspective. Nonetheless, research suggests that mothers and fathers have differential impacts on children's sports engagement and participation. A meta-analysis found that fathers are more likely to promote gender-stereotyped behavior than mothers, though the strength of this effect decreases with the age of the child (Lytton, \& Romney, 1991). Pressure from fathers is associated with decreased enjoyment in sports whereas there was no association with pressure from mothers (Kanters, \& Casper, 2007). These findings suggest that fathers have a unique role on child's pursuit of sports. Fathers tend to promote gender-stereotyped behavior, which can support boys' sports participation. However, fathers' support can be perceived by the child as pressure to perform and achieve, thereby undermining intrinsic enjoyment in the activity.

As socializing agents, parents shape child's competence beliefs and values for activities and thus their participation choices. Early family influences and opportunities provided may be critical for supporting the development of motivation and skills. However, less is known about the role parents play in supporting domain-specific self-concept beliefs and subjective task values as children get older (Eccles, 2007). Child motivation matters for how they choose to spend their leisure time, especially as autonomy for decision-making increases with age. In middle childhood and adolescence, children have more say in opting in and out of organized extracurricular activities. However, less is known about the role of parents and child motivation in sports participation choices from middle childhood through adolescence.

\section{Current Study}

Much research on youth participation in sports has focused on demographic factors (such as family socioeconomic status and gender) to the neglect of social-motivational influences (Simpkins, Davis-Kean, \& Eccles, 2005). This study examines the influence of parents' sportsrelated beliefs and behaviors and how they compare to children's motivational beliefs in predicting later organized sports participation in adolescence. Due to decreased parental influence and youth's motivation for extracurricular activities in adolescence, it is of interest how both factors are associated with whether youth decide to continue sports participation in adolescence and the depth (time spent) of participation (Eccles, 1993; Montemayor, \& Hanson, 1985). Furthermore, this study uses data from a longitudinal investigation that measures parent and child sports-related beliefs and behaviors across two developmental stages characterized by declines in child motivation and organized sports participation-middle childhood and adolescence (Eccles, 1993; Jacobs, Lanza, Osgood, Eccles, \& Wigfield, 2002). In addition, this study uses data collected from a sample of mothers and fathers to examine the role of both parental figures in relation to youth sports participation. 
This study addresses two research questions.

1) First, how are parents' sports-related beliefs (expectancies and values) and encouragement associated with children's expectancies and values for sports and participation in middle childhood?

2) Second, what factors measured in middle childhood continue to be predictive of children's participation in organized sports activities in adolescence-child motivation, parent encouragement, and/or parent beliefs?

We expect that parents' sports-related beliefs and encouragement, children's motivational beliefs, and time spent participating in organized sports activities are positively associated. It is also expected that children's expectancies and value for sports and parental encouragement and beliefs measured in middle childhood will be predictive of children's participation choices in adolescence (i.e., whether adolescents participate in sports and time spent participating).

\section{Methods}

\section{Participants}

This study examined data from Childhood and Beyond (CAB) study, a 13-year longitudinal fieldbased investigation (1987-1999) conducted by Eccles and colleagues at the University of Michigan. Data were collected from children and their parents and teachers from 10 schools in four school districts in Southeastern Michigan. The sample consisted of primarily White students from two-parent, intact, lower-middle- to middle-class families living in urban/suburban communities near Detroit. The mean family income ranged from $\$ 10,000$ to $\$ 80,000$, with a median range of $\$ 50,000$ to $\$ 59,000$.

Parent and child questionnaire data from Wave 4 (Spring 1990) and Wave 6 (Spring 1995) were included in this current study to compare changes in middle childhood (Wave 4) to adolescence (Wave 6). Children who completed the child questionnaire in both Waves 4 and 6 and whose parent(s) completed the parent questionnaire in both waves were included in this current study. Wave 4 had a total of 386 children with valid data in Grades 3, 4, and 6. Wave 6 had a total of 221 children with valid data in Grades 8, 9, and 10. The final, intact sample from which findings are reported included 160 mothers and 95 fathers, with 89 children having both mother and father data.

\section{Measures}

Composite measures of parent beliefs and children motivational beliefs at Waves 4 and 6 were created by averaging the items responses within each construct and wave. All questionnaire items were measured on a 7-point Likert scale except for the items assessing average time spent in organized sport activities (Table 1). 
Table 1

Childhood and Beyond Survey Items

Scale and Items

\section{Parent Beliefs}

How good is this child at sports?

Compared to other children, how much innate ability or talent does this child have in sports? How well do you think this child will do next year in sports?

How important is it to you that this child does well in sports?

\section{Parent Encouragement}

Indicate the extent to which you encourage playing competitive sports for this child.

\section{Children Motivation \\ Expectancies}

How good at sports are you?

If you were to list all the students your age from best to worst in sports, where would you put yourself?

How good would you be at learning something new in sports?

Compared to most of your other activities, how good are you at sports?

How well do you expect to do in your favorite sport this year?

Task value

For me, being good in sports is important.

Compared to your other activities (including schoolwork), how useful is learning sports?

Compared to most of your other activities, how important is it to be good in sports?

In general, I find playing sports interesting.

How much do you like sports?

\section{Children Sports Participation}

\section{Dichotomous}

Whether the child participated in organized sports activities that year

Frequency

About how many hours each week do you usually spend on taking part in organized sports?

(1=none; $8=21$ or more hours)

Note: All items were measured on a 7-point Likert scale unless stated otherwise.

Parent beliefs. Four items were used to measure parent perceptions of children's ability in sports and parent perception of the importance of sports. Example questions include, "How good is this child at sports?" and "How important is it to you that this child does well in sports?" The reliability of this 4-item scale was acceptable across parents and waves $(\alpha=.84-.85$ for mothers; $\alpha=.85-.87$ for fathers).

Parent encouragement. One item was used to assess parent encouragement: "Please indicate the extent to which you encourage playing competitive sports for this child ( 1 = strongly discourage; 7 = strongly encourage)."

Child motivation. Both children's expectancies and task values for sports were measured. Five items were used to assess children's expectancies or self-concept of ability in sports. For example, one question asked, "If you were to list all the students your age from worst to best in sports, where would you put yourself ( 1 = one of the worst; $7=$ one of the best)?" Five items 
were used to assess children's task value for sports. An example of a task value item is, "For me, being good in sports is... ( $1=$ unimportant; $7=$ important)." The reliability of the composite child motivation scale was acceptable across waves $(\alpha=.93$ for Wave 4; $\alpha=.95$ for Wave 6).

Child participation. The outcome variable, child participation, was operationalized in two ways. The first method measured participation as a dichotomous variable-whether or not the child participated in organized sports during particular academic years (i.e., Waves 4 and 6). The second operationalization of participation was average time spent participating in organized sports. Children were asked to report time spent "taking part in organized sports" in a typical week ( $1=$ none; $8=21$ or more hours).

Control variables. Parent reports provided information on average family income, parent education (highest level of educational attainment within a parental pair), and child gender, age, and ethnicity. These aspects were included in the analyses as control variables.

Analytic strategy. Pearson correlations were calculated to examine the association between parent beliefs, parent encouragement, and child motivation in middle childhood (Wave 4). Marginal effects logistic regression was used to determine which variables measured in middle childhood (Wave 4) predicted the dichotomous outcome, whether a child participated in organized sports activities in adolescence (Wave 6). Ordinary least squares (OLS) regression was used to examine whether parent beliefs, parent encouragement, and child motivation measured in middle childhood (Wave 4) predicted average weekly hours spent in organized sports activities in adolescence (Wave 6).

\section{Results}

To determine if parents' sports-related beliefs and encouragement were associated with children's motivational beliefs and participation in middle childhood, Pearson correlations were calculated (Table 2). Correlations among child participation, the variables of interest (parent encouragement, parent behavior, and child motivation), and child gender were positive and of moderate strength $(r=.35-.61)$. This indicates that males, parent beliefs, parent encouragement, and child motivation were positively associated with time spent in organized sports activities in middle childhood. 
Table 2

Pearson correlations among variables $(N=255)$

Measured at middle childhood (wave 4)

\begin{tabular}{|c|c|c|c|c|c|c|c|c|c|c|c|}
\hline & 1 & 2 & 3 & 4 & 5 & 6 & 7 & 8 & 9 & 10 & 1 \\
\hline \multicolumn{12}{|l|}{ Parent influences } \\
\hline $\begin{array}{ll}\text { 1. } & \text { Mother beliefs } \\
\text { 2. } & \text { Father beliefs } \\
\text { 3. } & \text { Mother } \\
\text { encouragement } & \text { Father } \\
\text { 4. } & \text { encouragement } \\
\end{array}$ & $\begin{array}{l}-- \\
.71 * * * \\
.45 * * * \\
.41 * * *\end{array}$ & $\begin{array}{l}.- \\
.48^{* * *} \\
.56^{* * *}\end{array}$ & $\begin{array}{l}-- \\
.46 * * *\end{array}$ & -- & & & & & & & \\
\hline \multicolumn{12}{|l|}{ Youth variables } \\
\hline $\begin{array}{ll}\text { 5. } & \text { Motivation } \\
\text { 6. } & \text { Participation } \\
\end{array}$ & $\begin{array}{l}.51 * * * \\
.35 * * *\end{array}$ & $\begin{array}{l}.70 * * * \\
.47 * * * \\
\end{array}$ & $\begin{array}{l}.38 * * * \\
.44 * * * \\
\end{array}$ & $\begin{array}{l}.44 * * * \\
.41 * * *\end{array}$ & $-\overline{-}-61 * * *$ & -- & & & & & \\
\hline \multicolumn{12}{|l|}{ Controls } \\
\hline $\begin{array}{ll}\text { 7. Male (youth) } \\
\text { 8. Youth age } \\
\text { 9. Youth ethnicity } \\
\text { 10. Family income } \\
\text { 11. Parent education }\end{array}$ & $\begin{array}{r}.10 \\
.00 \\
-.05 \\
.09 \\
-.05\end{array}$ & $\begin{array}{l}.25^{* *} \\
.16 \\
-.16 \\
.03 \\
-.02\end{array}$ & $\begin{array}{l}.23 * * * \\
-.07 \\
-.01 \\
.05 \\
.06\end{array}$ & $\begin{array}{l}.29 * * * \\
-.08 \\
-.07 \\
.03 \\
.02\end{array}$ & $\begin{array}{l}.39 * * * \\
.13 \\
-.11 \\
.21 * * \\
.00\end{array}$ & $\begin{array}{l}.41 * * * \\
-.07 \\
.00 \\
.06 \\
.08 *\end{array}$ & $\begin{array}{l}-- \\
-.02 \\
.05 \\
.00 \\
-.04\end{array}$ & $\begin{array}{l}-- \\
-.01 \\
- \\
.08^{*} \\
-.01 \\
\end{array}$ & $\begin{array}{l}-- \\
.01 \\
.14 * * *\end{array}$ & $\begin{array}{l}-- \\
.44 * * *\end{array}$ & -- \\
\hline
\end{tabular}

${ }^{*} p<0.05,{ }^{*} p<<0.01, * * * p<0.001$

a Continuous variable measuring average time spent on organized sports activities per week

b Continuous variable with White coded as " 1 " and other ethnicities coded as higher numbers.

Marginal effects logistic regression was used to predict the dichotomous outcome, whether the child participated in organized sports in adolescence during Wave 6 (Table 3). Mother encouragement and father sports-related beliefs reported in middle childhood were associated with a significant percentage point increase in the probability of the child being involved in organized sports activities in adolescence. A one-unit increase in mother encouragement was associated with a $7 \%$ increase in the probability of the child participating in sports in adolescence. A one-unit increase in father beliefs was associated with an $18 \%$ increase in the probability of the child participating in sports in adolescence. Previous child motivation and whether the child participated in organized sports in middle childhood were not predictive of later participation. 


\section{Table 3}

Marginal effects logistic regression results ( $N=153$ Mothers, 93 Fathers) for middle childhood (Wave 4) measures predicting whether youth reported participating in organized sports in adolescence (Wave 6).

\begin{tabular}{|c|c|c|}
\hline & $\begin{array}{c}\text { Child-Reported } \\
\text { Participation } \\
\text { w/ Maternal Sample }\end{array}$ & $\begin{array}{c}\text { Child-Reported } \\
\text { Participation w/ Paternal } \\
\text { Sample }\end{array}$ \\
\hline Mother beliefs & $\begin{array}{r}0.05 \\
(0.04) \\
\end{array}$ & \\
\hline Father beliefs & & $\begin{array}{l}0.18^{*} \\
(0.07) \\
\end{array}$ \\
\hline Mother encouragement & $\begin{array}{l}0.07^{*} \\
(0.03) \\
\end{array}$ & \\
\hline Father encouragement & & $\begin{array}{r}0.03 \\
(0.04)\end{array}$ \\
\hline Childhood motivation & $\begin{array}{r}0.08 \\
(0.04) \\
\end{array}$ & $\begin{array}{r}0.00 \\
(0.06) \\
\end{array}$ \\
\hline Childhood participation & $\begin{array}{c}0.09 \\
(0.12) \\
\end{array}$ & $\begin{array}{c}0.04 \\
(0.15) \\
\end{array}$ \\
\hline \multicolumn{3}{|l|}{ Background information } \\
\hline Male & $\begin{array}{l}-0.15 \\
(0.09)\end{array}$ & $\begin{array}{l}-0.19 \\
(0.11)\end{array}$ \\
\hline Age & $\begin{array}{r}0.04 \\
(0.03) \\
\end{array}$ & $\begin{array}{r}0.03 \\
(0.05) \\
\end{array}$ \\
\hline Avg. Family Income & $\begin{array}{r}0.00 \\
(0.03)\end{array}$ & $\begin{array}{r}0.00 \\
(0.04)\end{array}$ \\
\hline Parent Education & $\begin{array}{r}0.03 \\
(0.03)\end{array}$ & $\begin{array}{r}0.03 \\
(0.04)\end{array}$ \\
\hline
\end{tabular}

To examine whether child motivation or parent encouragement and beliefs measured in middle childhood are predictive of sports participation in adolescence, OLS regression analysis was used. OLS regression was used to predict weekly average time spent participating in organized sports in adolescence (Table 4). Net of other variables in the equation, mother encouragement and child motivation reported in middle childhood were positively associated with weekly time spent in sports during adolescence. Father beliefs reported in middle childhood and being female were positively associated with time spent in organized sports in adolescence. 
Table 4

Standardized OSL regression results ( $N=160$ Mothers, 95 Fathers) for middle childhood (Wave 4) measures predicting average sports participation frequency in adolescence (Wave 6).

\begin{tabular}{|l|c|c|}
\hline & $\begin{array}{c}\text { Child-Reported } \\
\text { Participation } \\
\text { W/ Maternal Sample }\end{array}$ & $\begin{array}{c}\text { Child-Reported } \\
\text { Participation w/ Paternal } \\
\text { Sample }\end{array}$ \\
\hline Mother beliefs & 0.17 & $0.29 *$ \\
\hline Father beliefs & & \\
\hline Mother encouragement & $0.27^{* *}$ & 0.12 \\
\hline Father encouragement & & 0.27 \\
\hline Childhood motivation & $0.24 *$ & -0.12 \\
\hline Childhood participation & -0.13 & \\
\hline Background information & & $-0.26 *$ \\
\hline Male & -0.13 & 0.06 \\
\hline Age & 0.01 & -0.14 \\
\hline Ethnicity & -0.14 & -0.06 \\
\hline Avg. Family Income & -0.01 & -0.02 \\
\hline Parent Education & 0.05 & .285 \\
\hline R2 & .232 & \\
\hline$* p<.05$. & & \\
\hline
\end{tabular}

An exploratory, multiplicative regression model was also analyzed to determine if parent beliefs and encouragement interacted with child gender. The gender interaction terms were not significant.

\section{Discussion}

Results from this longitudinal study showed that, in middle childhood, time spent in organized sports activities is concurrently and positively associated with parent encouragement and beliefs (i.e., perceived importance of sports and perceived child ability) and child motivational beliefs for sports. When predicting whether a child continues to participate in sports as an adolescent or not, middle childhood assessments of mother encouragement and father beliefs were positive predictors. In contrast, none of the child-reported motivation measures were significant predictors of whether or not adolescents participated in organized sports during adolescence. However, when predicting the amount of time spent in organized sports during adolescence, child motivational beliefs (i.e., perceived self-abilities and value for sports) as well as mother encouragement and father beliefs were significant predictors.

Although sports participation has been shown to decline from middle childhood through adolescence, it remains the most common form of organized activity involvement for young people (Mahoney, Harris, \& Eccles, 2005). Consistent with a bioecological perspective to organized activity participation (e.g., Mahoney, et al., 2009) the findings from this study 
suggest that both the child and his/her parents play an active role in the ongoing process of activity participation. Results from this study indicate that this process can only be identified from a developmental perspective using longitudinal data. The findings point to the possibility that parental influences linked to sports participation in middle childhood may be unique and continue to exert an influence on children's involvement in organized sports years later during adolescence. Whether adolescent participation is measured dichotomously or continuously, fathers' beliefs and mothers' encouragement toward activity involvement years earlier appear to have an influence on later participation in the expected direction.

Moreover, for reasons that are not known, mothers and fathers seemed to influence their child's participation through different behavior processes (i.e., encouragement and values, respectively). That there are multiple routes to support participation is potentially good news for those young people residing in single parent families and those for whom one parent is unable or unwilling to provide support. In this case, the motivational system favoring adolescent sport participation may be open to influence from more than one family subsystem.

The finding that parental behaviors affect youth decision-making concerned with future sport participation raises an important new question for the field; namely, why do some parents support their child's participation in sports when others do not? Although we do not have data on this point, it seems likely some portion of parent support is derived from their own past experiences as activity participants. Parents who themselves participated in organized sports might be most likely to hold the belief that activity participation is valuable and encourage their child to participate. In this case, parent belief and encouragement fall along gender stereotypical patterns, with father's values and mother's encouragement reaching statistical significance in relation to the child's sport participation in adolescence. Although Title IX legislation became law over 40 years ago and is meant to ensure equal educational opportunities for boys and girls, including participation in sport, in practice it has not produced an entirely "level playing field" (e.g., Sabo, \& Veliz, 2011). This is consistent with the current findings that parent support is predictive of later participation, but the type of support provided differs for mothers and fathers.

However, the greatest prediction of the amount of sports participation in adolescence involves obtaining information from both the child and his/her parents. This suggests that middle childhood may be a relatively open period for young people to develop their interests in organized sports. When this interest is supported by parent behaviors during childhood whether directly or indirectly - it may set in motion a long-term process that favors continued participation, rather than activity dropout, during adolescence.

With respect to the child, motivation for sport during middle childhood predicts the weekly frequency of sport participation during adolescence. Therefore, individual motivation is part of an active process whereby the child himself or herself significantly affects his or her own developmental trajectory of participation and associated outcomes. The upshot is that individual motivations for organized sport participation developed early on may have a lasting impact that increases the stability of participation over time. According to existing research, this is important because adolescent participation may, in turn, help to offset risks and promote competence in the physical, social, and educational domains during adolescence (Mahoney, et al., 2009).

In addition, we note that some popular writers contend that youth are over-scheduled in organized activities such as sports. (e.g., Elkind, 2001; Rosenfeld, \& Wise, 2000). The overscheduling is thought to be driven by adults, including parents, who push their children to 
participate beyond their desire. Findings from this study indicate this is not ordinarily the case insofar as the relation between child and parent affinity for sports involvement was positive and statistically significant. In other words, when it comes to amount of sports involvement, parents and their children tend to see eye to eye or are at least looking in the same direction. In fact, it may require a high degree of synergy and agreement between parent(s) and youth to devote considerable amounts of time to sports, which thereby leads to positive developmental outcomes (Mahoney, et al., 2005). Nonetheless, the associations are only moderately strong indicating that, in at least some cases, room for disagreement exists about the amount of time youth spend participating in sports within families. Future work might help to identify whether the over-scheduling phenomenon is observed in families that are discordant about the value of time children and adolescents devote to sports.

Finally, in terms the most significant limitations of this study, we note that the CAB data were initially collected over 15 years ago and it is possible that a more recent cohort of nationally representative families would demonstrate a different, less stereotyped connection between parent support of youth sports and their children's actual participation. Thus, we call for efforts to replicate the current study using more recently collected and nationally representative data or for meta-analytic study that can synthesize these findings amidst related studies in the existing literature to be carried out.

\section{References}

Barber, B.L., Eccles, J.S., \& Stone, M.R. (2001). Whatever happened to the jock, the brain, and the princess?: Young adult pathways linked to adolescent activity involvement and social identity. Journal of Adolescent Research, 16(5), 429-455.

Bohnert, A., Fredricks, J., \& Randall, E. (2010). Capturing unique dimensions of youth organized activity involvement: Theoretical and methodological considerations. Review of Educational Research, 80, 576-610.

Bois, J.E., Brustad, R.J., Chanal, J.P., \& Trouilloud, D.O. (2005). Parents' appraisals, reflected appraisals, and children's self-appraisals of sport competence: A yearlong study. Journal of Applied Sport Psychology, 17, 273-289.

Eccles, J.S. (1993). School and family effects on the ontogeny of children's interests, self perceptions, and activity choice. In J. Jacobs (Ed.), Nebraska symposium of motivation: Developmental perspectives on motivation (pp. 145-208). Lincoln, NE: University of Nebraska Press.

Eccles, J.S. (1994). Understanding women's educational and occupational choices: Applying the Eccles, et al., model of achievement-related choices Psychology of Women Quarterly, 18, 585-609.

Eccles, J.S. (2007). Families, schools, and developing achievement-related motivations and engagement. In J.E. Grusec \& P.D. Hastings (Eds.), Handbook of socialization: Theory and research (pp. 665-691). New York: Guilford.

Fletcher, A.C., Elder, G.H., Jr., \& Mekos, D. (2000). Parental influences on adolescent involvement in community activities. Journal of Research on Adolescence, 10, 29-48. 
Fredricks, J.A., \& Eccles, J.S. (2002). Children's competence and value beliefs from childhood through adolescence: Growth trajectories in two male-sex-typed domains. Developmental Psychology, 38, 519-533.

Fredricks, J.A., \& Eccles, J.S. (2005). Family socialization, gender, and sports motivation and involvement. Journal of Sport \& Exercise Psychology, 27, 3-31.

Fredricks, J.A., \& Eccles, J.S. (2006). Extracurricular involvement and adolescent adjustment: Impact of duration, number of activities, and breadth of participation. Applied Developmental Science, 10(3), 132-146.

Harrison, P.A., \& Narayan, G. (2003). Differences in behavior, psychological factors, and environmental factors associated with participation in school sports and other activities in adolescence. Journal of School Health, 73(3), 113-120. doi: 10.1111/j.1746 1561.2003.tb03585.x.

Huebner, M.A., \& Mancini, J. (2003). Shaping structured out-of-school time use among youth: The effects of self, family, and friend systems. Journal of Youth and Adolescence, 32, 453-463.

Jacobs, J.E., \& Eccles, J.S. (2000). Parents, task values, and real-life achievement related choices. In C. Sansone, \& J.M. Harackiewicz (Eds.), Intrinsic and extrinsic motivation: The search for optimal motivation and performance (pp. 405-439). San Diego: Academic Press.

Jacobs, J.E., Lanza, S., Osgood, D.W., Eccles, J.S., \& Wigfield, A. (2002). Changes in children's self-competence and values: Gender and domain differences across grades one to twelve. Child Development, 73, 509-527.

Jacobs, J.E., Vernon, M.K., \& Eccles, J. (2005). Activity choices in middle childhood: The role of gender, self-beliefs, and parents' influence. In J.L. Mahoney, R.W. Larson, \& J.S. Eccles (Eds.), Organized activities as contexts of development: Extracurricular activities, after-school and community programs (pp. 235-254). Hillsdale, NJ: Erlbaum.

Kanters, M.A., \& Casper, J. (2007). Supported or pressured?: An examination of agreement among parent's and children on parent's role in youth sports. Journal of Sport Behavior, $31(1), 64-80$.

Larson, R.W. (2000). Towards a psychology of positive youth development. American Psychologist, 55, 170-183.

Lytton, J., \& Romney, D.M. (1991). Parents' differential socialization of boys and girls: A meta analysis. Psychological Bulletin, 2, 267-296.

Mahoney, J.L. (2011). Adolescent summer care arrangements and risk for obesity the following school year. Journal of Adolescence, 34, 737-749.

Mahoney, J.L., Harris, A.L., \& Eccles, J.S. (2006). Organized activity participation, positive youth development, and the over-scheduling hypothesis. SRCD Social Policy Report, 20 (4), 1-31. 
Mahoney, J.L., Larson, R.W., Eccles, J.S., \& Lord, H. (2005). Organized activities as developmental contexts for children and adolescents. In J. Mahoney, R. Larson, \& J.S. Eccles (Eds.), Organized activities as contexts of development: Extracurricular activities, after-school, and community programs (pp. 3-22). Hillsdale, NJ: Erlbaum.

Mahoney, J.L., Vandell, D.L., Simpkins, S.D., \& Zarrett, N.R. (2009). Adolescent out-of school activities. In R.M. Lerner \& L. Steinberg (Eds.), Handbook of Adolescent Psychology ( ${ }^{\text {rd }}$ ed.). Vol. 2: Contextual influences on adolescent development (pp. 228267). Hoboken, NJ: Wiley \& Sons.

Montemayor, R., \& Hanson, E.A. (1985). A naturalistic view of conflict between adolescents and their parents and siblings. Journal of Early Adolescence, 5, 23-30.

National Household Survey on Drugs Abuse Report. (2002). Team sports participation and substance use among youths. Retrieved from http://www.samhsa.gov/data/2k2/athletes/athletes_DrugUse.htm

Paikoff, R.L., \& Brooks-Gunn, J. (1991). Do parent-child relationships change during puberty? Psychological Bulletin, 110(1), 47-66.

Pugliese, J. (2011). Parent-child relationships and parental tactic use: The socialization of physical activity within the context of an expectancy-value model (Unpublished doctoral dissertation). Arizona State University, AZ.

Pugliese, J., \& Tinsley, B. (2007). Parental socialization of child and adolescent physical activity: A meta-analysis. Journal of Family Psychology, 21(3), 331-343.

Sabo, D., Veliz, P. (2011). Progress without equity: The provision of high school athletic opportunity in the United States by gender 1993-94 through 2005-06. Women's Sports Foundation.

Schunk, D.H., Pintrich, P.R., \& Meece, J. (2008). Motivation in education: Theory, research, and application ( $3^{\text {rd }}$ ed.). Upper Saddle River, NJ: Merrill Prentice-Hall.

Simpkins, S.D., Davis-Kean, P.E., \& Eccles, J.E. (2005). Parents' socializing behavior and children's participation in math, science, and computer out-of-school activities. Applied Developmental Science, $9(1), 14-30$.

Wigfield, A., \& Eccles, J.S. (2000). Expectancy-value theory of motivation. Contemporary Educational Psychology, 25, 68-81. doi: 10.1006/ceps.1999.1015

(C) Copyright of Journal of Youth Development $\sim$ Bridging Research and Practice. Content may not be copied or emailed to multiple sites or posted to a listserv without copyright holder's express written permission. Contact Editor at: patricia.dawson@oregonstate.edu for details. However, users may print, download or email articles for individual use.

ISSN 2325-4009 (Print); ISSN 2325-4017 (Online) 